\title{
IN-SITU OBSERVATION OF THE REACTION BETWEEN IRON AND CARBON IN TEM
}

\author{
N. Ishikawa*, T. Aoyagi*, T. Kimura*, T.Harada** and T.Inami** \\ *Advanced Nano Characterization Center, National Institute for Materials Science (NIMS), \\ 3-13, Sakura, Tsukuba, Ibaraki 305-0003 Japan. \\ **Faculty of Engineering, Ibaraki University, 4-12-1, Nakanarusawa-cho, Hitachi 316-8511 \\ Japan.
}

The carbon is one of the most important materials in steel industry. The microstructure change during iron and steel making is not still unclear because it was impossible to see the reduction of iron oxides or carburization directly in TEM because of the difficulty of making specimens. We have developed the making TEM specimens to realize the in-situ analysis for the reduction of the iron-oxides by solid carbon applying the deposition of carbon. The carbon is also soluble into iron easily and we expected to realize the in-situ observation of the reaction between iron and carbon in TEM in the similar way of specimen preparation. The purpose of our study is to carry out the in-situ analysis of the reaction between carbon and iron in TEM

The preparation of TEM specimen is most important in this study. The clean surface of iron is necessary to contact with carbon. FIB was employed to get the flat and clean surface because it is easy to find the polishing area. The dislocations due to the damage of ion bombardments are also induced into the specimen, but the transformation to amorphous in case of using oxides were avoided. The specimens were removed to the deposition apparatus in air after polishing as soon as possible to minimize the surface contamination. The thickness of carbon was $0.5-1 \mu \mathrm{m}$. Final thinning was carried out also using FIB to get the thin area locally. The in-situ experiment at elevated temperature was carried out in the JEM-2000FX. EDS and EELS which installed in JEM-2100F and JEM-3000F respectively were also used for analysis of the component

The reaction between carbon and iton started appoloximately above $773 \mathrm{~K}$ and the rate of reaction became faster as incleasing the temperature. Figure.1 shows bright field images of continuous observation of the structural change at the boundary between iron and carbon which was kept at $823 \mathrm{~K}$ up to $90 \mathrm{~min}$, a) before heating, b) after 10 minutes, c) after 30 minutes and after 90 minutes in d). During heating, the precipitation of small particles which was observed in $b$ ) occurred and they grew into the carbon layer. The growth of the reaction stopped by the detachment between carbon and iron or coming of precipitates at the edge of carbon layer as shown in d). 
EDS showed that the component of precipitates was almost iron and no carbon was found. To confirm this result, EELS was also used. Figure 2 shows mapping of EELS around the precipitates. The images of mapping was same as the result of EDS and there found no signal of carbon but iron in the precipitates. These results indicated that iron diffused into the carbon layer and exchanged with carbon. But it is unclear destination of exchanged carbon because the solubility of carbon in iron is extremely low at the range of observed temperature. The observation was done at much lower temperature than the common industrial way for carburization. It is cleared that the phenomenon of iron precipitation into the carbon is much different from the carburization.

\section{REFERENCES}

[1] N. Ishikawa, K. Furuya, N. Mitsuoka and T. Inami : ISIJ Int. 46 (2006), 1106

[2] N. Ishikawa, K. Furuya, T. Aoyagi, N. Mitsuoka and T. Inami: Tetsu to Hagane, 192(2006), 48.

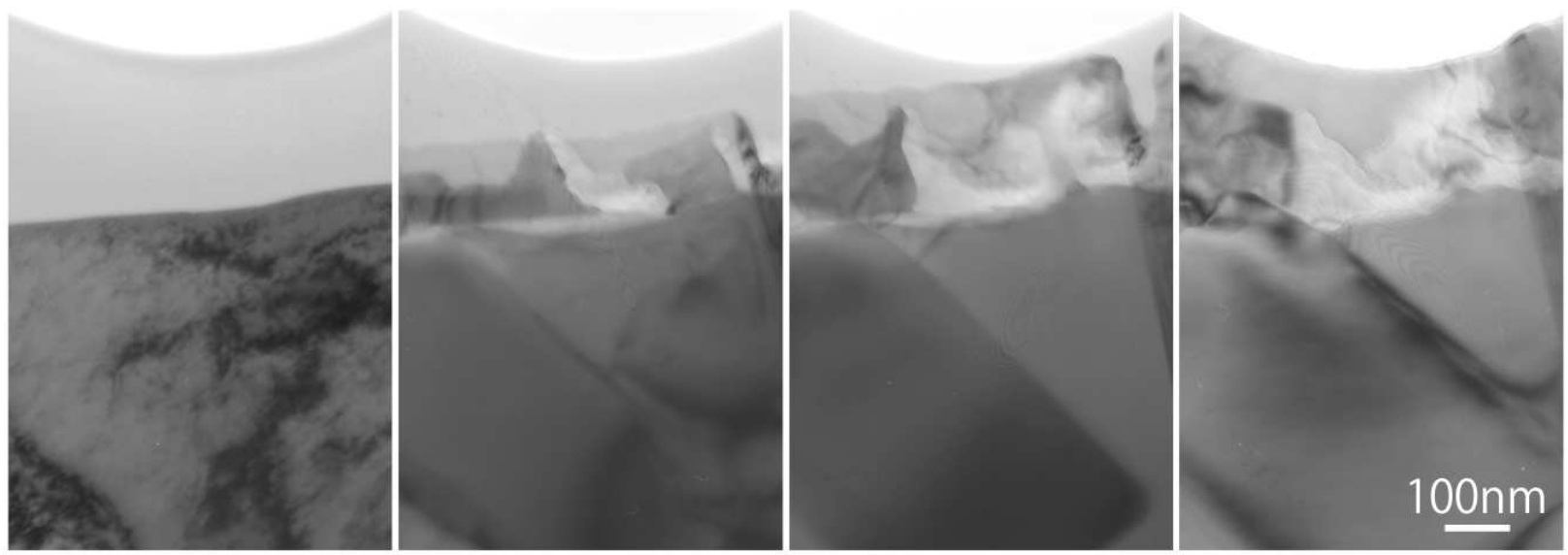

Fig.1. TEM photograph of the change of boundary between a iron and a carbon kept at $823 \mathrm{~K}$ up to $90 \mathrm{~min}$. a) just reached $823 \mathrm{~K}$, b) after 10 minutes, c) after 30 minutes and (d) after 90 minutes.

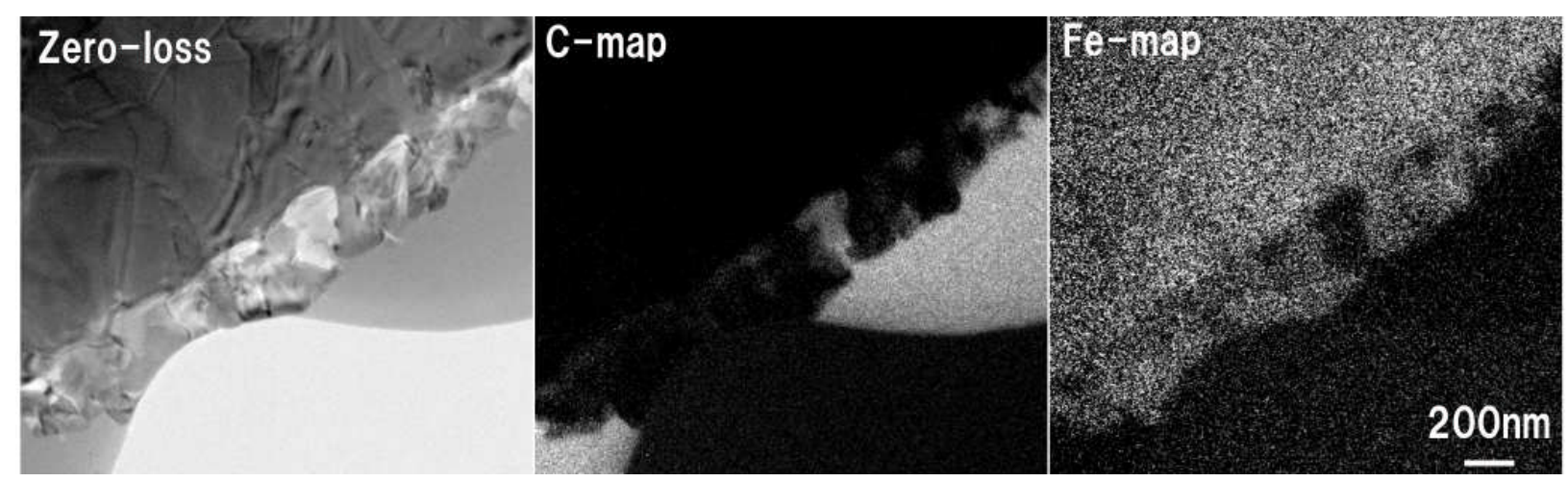

Fig.2. EELS mapping of carbon and iron. 